\title{
Digital Competence and Web Technologies: Analysis of a Research Project and its Instruments *
}

\author{
Antonio Cartelli \\ Laboratory for Teaching and Learning Technologies \\ Department of Human and Social Sciences \\ University of Cassino - Italy
}

\begin{abstract}
cartan@unicas.it
* This work has been made possible under the grant n. 2006112810 of the Italian Ministry for University and Research (MUR), DM n. 582/2006 of Mar 24, 2006.
\end{abstract}

\begin{abstract}
The paper reports on the features of the framework for digital literacy support and documentation, developed within a research project the author is working on, with some colleagues in other Italian universities.

First a short introduction on the features of today society often called "knowledge society" is reported, and the problems of digital divide and digital literacy are discussed. Soon after the research project, planned and carried out under the coordination of the University of Florence, for the development of the instruments to be devoted to the construction of a digital competence is drafted. To let the reader better understand how the project situates in the panorama of today studies, a synthesis of the international works on those topics is described, with a special attention to the connections between them and the new generations' digital basic skills. The description of the general features of the project and of the instruments the author hypothesized for the hitting of the attained results are then discussed, while paying attention to the information systems to be used for the creation of an online testing system and for the management of digital literacy bibliography.
\end{abstract}

The paper ends with some considerations on the evolution of the project and the possible results from it as regards informing science.

Keywords: digital competence, digital divide, digital literacy, information literacy, information system, web technology.

Material published as part of this publication, either on-line or in print, is copyrighted by the Informing Science Institute. Permission to make digital or paper copy of part or all of these works for personal or classroom use is granted without fee provided that the copies are not made or distributed for profit or commercial advantage AND that copies 1) bear this notice in full and 2) give the full citation on the first page. It is permissible to abstract these works so long as credit is given. To copy in all other cases or to republish or to post on a server or to redistribute to lists requires specific permission and payment of a fee. Contact Publisher@InformingScience.org to request redistribution permission.

\section{Introduction}

It is well known that IT and ICT modified the way mankind managed information and the stile of communicating since their first appearance; they also introduced deep changes in the people's representation of reality, their knowledge structures and their learning construction. 
The consciousness of the above changes induced the transformation of the appellation until then adopted of "information society", mostly centered on the management of information, into the newer one of "knowledge society", where greater importance is attributed to the way people exchange information, develop new skills for acquiring it and build knowledge; otherwise stated the term "knowledge society" aims at describing the environment we are immersed in, which is marked from the new need of managing information for building effective new knowledge, and the context we have to deal with.

Due to the importance that ICT and the related skills have in the knowledge society it can be easily understood why the digital divide is today a pedagogical emergency all over the world. Many studies have been carried out both for better defining the meaning and the features of the phenomenon and for finding the instruments and the strategies to be adopted, just from the first school levels, to help the new generations in overcoming the problems they can meet in the use of new technologies.

As regards the features of the digital divide one can easily agree with its many faces, all involving the problem of accessibility, but, for the importance they have in what follows, we will remember here only the following three aspects (Bindé 2005; Guidolin 2005; Kling 1998; Lévy 1997):

1) the lack of technology, which induces a gap between people who can access the communicating and computing instruments and those who cannot,

2) a more complex perspective, which assigns to technology only a part, relevant but not exclusive, in the definition and featuring of the digital divide; the gap derives now from preexisting differences between the people who are able in the use of technologies and those who are not,

3) at last we have the gap between those who master content management (information, knowledge, know how etc.) and the related services, strongly based on the use of technology, and those who don't.

Otherwise stated the problem of the access to information is today seen as depending not only on the "lack of technology" but on many other different gaps, like the cultural, educational and psychological ones.

Furthermore, the problem of the access to information is intertwined with the critical and conscious use of the information; this problem cannot be separated from the others and has to be connected to the following further problems:

a) the digital divide, while evidencing differences and separations among subjects in everyday life, enhances the problem of the construction of scientific knowledge and influences the acquisition of a meaningful learning (as defined by D.P. Ausubel, 1990). This is an old and well known problem, which has been widely studied and analyzed but never completely explained and solved. In the '70s and ' 80 s, in fact, after the diffusion of the mass school, the problem of the difficulties the students met while approaching disciplinary knowledge already emerged. This problem was evidenced both in well settled disciplines and topics describing natural phenomena and in new fields of science like IT and ICT;

b) two different elements influence the access to information and its management.

First, the cultural frames within which the problems are analyzed:

- cognitivist the one for the description of scientific knowledge construction,

- socio-constructivist the one studying the digital divide. 
Second, new technologies play a relevant role in the structure and analysis of the above situations because:

1. people are now submerged from great amount of information, often redundant,

2. the filtering and selecting mechanisms of information are poor and sometimes inefficient,

3. the information overload generates trouble conditions and shifting in the subjects' interpretation frames (Wurman, 2001).

The same problems become more and more evident today, in Western countries, where teachinglearning strategies strongly based on the systematic use of ICT are widely spreading. It is now growing, in fact, the number of the scholars who are studying e-learning contexts (where they are present from more time) with a special attention to:

1. the dependence of students' performances from their learning styles,

2. the dependence of students' performances from teaching/tutoring styles,

3. the structure and use of evaluation and assessment information systems like e-portfolios.

The considerations reported above induced professor Antonio Calvani at the University of Florence, Italy, to propose to the author and to other colleagues: Rocco Quaglia at the University of Turin and Antonio Iannaccone at the University of Salerno, the creation of a research group, to work on the digital competences of young people and their different dimensions.

The people involved in the project were persuaded of the importance that social representations, expectations and attributions of meaning by the actors of the learning processes had on studentstechnologies interactions. Furthermore, they thought that other physical/objective factors could intervene on the development of the right access to the Internet, like for example:

a) psycho-social elements directly connected to the changes in teaching functions, induced from IT and ICT (i.e., self-perception and perception of the teacher's function, authority crisis etc.),

b) motivational and emotional aspects (inadequacy, anxiety etc.)

The research project, entitled "Internet and School: concerns with the access, equal policy and information management", aimed at answering to the above questions or some among them and at the development of suitable instruments for making easier for students the acquisition of digital competences. The complexity of the work suggested the planning of a biennial project which was proposed to the Italian Ministry of University and Research for funding; it obtained a grant under the form of co-financing and it has actually overcome its first year of life.

It is not in the aims of this paper the detailed analysis of the features of the whole project but a survey of the role played from the local unit of Cassino and its engagement is important for what follows. The most important works to be carried out from the local unit were:

1. the analysis of the literature on the following topics: Digital divide, Digital literacy, Digital competence and, what's more, the role of ICT introduction in the school, in the respect of an ecology of information, the right use of information repositories and search engines. The study involved also the Florence research unit and aimed at the construction of a solid bibliographical repository for these documents, to be made available on line to everyone,

2. the definition of the procedures and the planning/creation of the information systems to be used for testing and verifying the reference hypotheses in the theoretical model; obviously, the system had to be flexible enough to avoid the exclusion of possible new ideas which could emerge during the study evolution. At last, special attention had to be de- 
voted to the critical access to information (Learning Objects, information systems, Semantic Web etc.),

3. the planning and carrying out of inquiries (involving the schools in the neighborhood of the university of the local unit) to test, verify and possibly complete the emerging theoretical model; not less important was the finding of the best practices to be adopted in the use of the online instruments,

4. the carrying out of research products (both on paper and electronic) to spread and share in all educational contexts, to make easier for students and teachers the access to Internet resources and help them in overcoming the difficulties they could meet at school.

In what follows the many aspects drafted above are analyzed and discussed.

\section{From ICT Literacy Studies to the First Results for the Research Project}

The importance of new technologies in today society led many scholars and institutions to analyze the way people and especially students learned to use IT and ICT in everyday life and especially at school. Many conceptual models were also developed to describe the features of new literacy proposals involving IT and ICT and the most relevant ones are reported here.

The Committee on Information Technology of the Computer Science and Telecommunications Board on the US National Research Council (1999) published the report "Being fluent with Information Technology"; as a result of this report educational institutions were explicitly invited to propose to the students training activities on the abilities specifically needed for the information society.

The Association of College and Research Libraries (2000) proposed the following definition for information literacy: "the group of skills needed for individual development in modern-day societies" and described the features of these skills.

The UNESCO (2002), on another hand, defined media education as that education allowing people to develop the understanding of the means of communication used in their society and setting them along the path for the acquiring of the necessary skills which are needed to use these means in relation to others. UNESCO considers these skills as an essential part of the civic training.

The ETS (2002) by working at the International ICT Literacy Panel developed a framework within which it defined ICT literacy and provided the foundation for the design and conduct of large-scale assessments and diagnostic tests. For ETS the literacy in ICT has the following meaning: "digital technology, communications tools, and/or networks, to access, manage, integrate, evaluate and create information in order to function in a knowledge society".

The basic differences between the above proposals can be grouped in the following two categories (Tornero, 2004):

- $\quad$ Scope: The ACRL proposal refers to information in general, regardless of the means through which it may be accessed; UNESCO refers to the means of communication in a broader sense; ETS confines itself to digital means;

- $\quad$ Framework of applicability: UNESCO makes its proposal within a framework of democratic society, and therefore within a collective context; the ACRL and the ETS make their proposals within the framework of individual competence, which is cognitive and technological. 
Otherwise stated, the way by which the different documents look at digital literacy can be synthesized in Table 1 (Tornero, 2004):

\begin{tabular}{|c|c|c|c|}
\hline \multicolumn{4}{|c|}{ Table 1: Synthesis of the different proposals for ICT literacy } \\
\hline Processes & ETS Framework & $\begin{array}{c}\text { UNESCO } \\
\text { Media Education }\end{array}$ & $\begin{array}{l}\text { Association of College and } \\
\text { Research Libraries }\end{array}$ \\
\hline Selection & & Ability to select & $\begin{array}{l}\text { Recognize and determine the } \\
\text { extent of the information that } \\
\text { is needed }\end{array}$ \\
\hline Access & $\begin{array}{l}\text { Access: be familiar } \\
\text { with way of gathering } \\
\text { information }\end{array}$ & $\begin{array}{l}\text { Access: real possibility of } \\
\text { accessing the media and } \\
\text { producing with them }\end{array}$ & $\begin{array}{l}\text { Efficient access to the infor- } \\
\text { mation required }\end{array}$ \\
\hline $\begin{array}{l}\text { Integration/ } \\
\text { Evaluation }\end{array}$ & Integrate/ Evaluate & $\begin{array}{l}\text { Interpretation: of the mes- } \\
\text { sages and their values } \\
\text { Analysis: critical abilities } \\
\text { towards the media } \\
\text { Identification: of the } \\
\text { sources to understand } \\
\text { intentions and objectives }\end{array}$ & $\begin{array}{l}\text { Evaluate the information and } \\
\text { its sources } \\
\text { Incorporate the selected in- } \\
\text { formation into the base of } \\
\text { knowledge }\end{array}$ \\
\hline Management & $\begin{array}{l}\text { Manage by applying a } \\
\text { classification diagram }\end{array}$ & & $\begin{array}{l}\text { Use the information effec- } \\
\text { tively on the basis of an es- } \\
\text { tablished objective } \\
\text { Classify, store, manipulate } \\
\text { any information gathered or } \\
\text { generated }\end{array}$ \\
\hline $\begin{array}{l}\text { Creation/ } \\
\text { Production }\end{array}$ & $\begin{array}{l}\text { Create: generate in- } \\
\text { formation }\end{array}$ & $\begin{array}{l}\text { Access to production us- } \\
\text { ing the media }\end{array}$ & $\begin{array}{l}\text { Restructure and generate } \\
\text { information }\end{array}$ \\
\hline
\end{tabular}

If the above ways of looking at IT and ICT knowledge and skills aim at having the features of literacy, they had to be addressed to teaching and education. This operation has many consequences on the organization of teachers' work:

a) the introduction of this form of literacy reinforces the change in everyday teaching already started more than twenty years ago. In the 70s' by following the cognitivist psychopedagogical paradigm and Bloom taxonomies (1984) teachers could define the targets of their teaching activities, plan their everyday work or make the instruments for the evaluation of teaching in a positivistic and global style (i.e., they could adopt a top-down approach in planning their work). Recently the evaluation and certification of the competences has become more and more important, both in professional contexts and educational world, and a change in the framework of teaching activity was needed. On the first hand the target of teaching is defined with respect to a given knowledge domain (i.e., when using taxonomies), on the second hand the development of competence has a more complex structure, it becomes transversal with respect to different discipline domains and has social features based on the real contexts it develops in;

b) the practical implementations of the concept of Digital Competence only partially succeeds in answering to the needs and expectations of people and institutions. The success of the many licences today available for the certification of the skills in computer use (European Computer Driving Licence - ECDL, first of all) are an indirect demonstration of the prevalence of a commercial reference model in the society (i.e., to learn how to use a special software product), which has little or no educational value at all. 
On the basis of the above considerations the research group started a systematic work for the development of the questions to be submitted to the students at different school levels; it was hypothesized, in fact, that the analysis of the answers could help in drafting the framework to work on, that is, to have information on the students' ICT skills (both acquired at school or not) and/or on the different levels of information management that ICT could induce in them.

It is beyond the aims of this paper the analytical discussion of the different contributions which enriched the first surveys and produced the feedbacks for the improvement of the questionnaires but some conclusions are reported in what follows.

Eight months after the project started and some hundreds students answered to different questionnaires on paper, a first framework for the analysis of students' answers was obtained; it looked good enough to define the enquiry areas and proceed with the creation of an on line questionnaire to be widely used all over the nation and internationally. The areas were the technological, the cognitive and the ethical ones and were used to create special sections in the final questionnaire.

In the technological section the questions concerning a formal knowledge of the technology, like computer structure, hardware and software were neglected. On the contrary, the items in the test focused on the understanding of common situations, like the ones people can meet in everyday life and/or working directly at the computer; they presuppose concrete problem solving skills.

The cognitive section can be identified with the Information Literacy (i.e., the ability in processing, managing and reading, together with the critical evaluation of texts, data, information and sources). The items in this section need general cognitive skills from the students to be solved (i.e., mostly linguistic or logic-linguistic competences): there could be high correlation between the results from this test and more specific tests on the same topics.

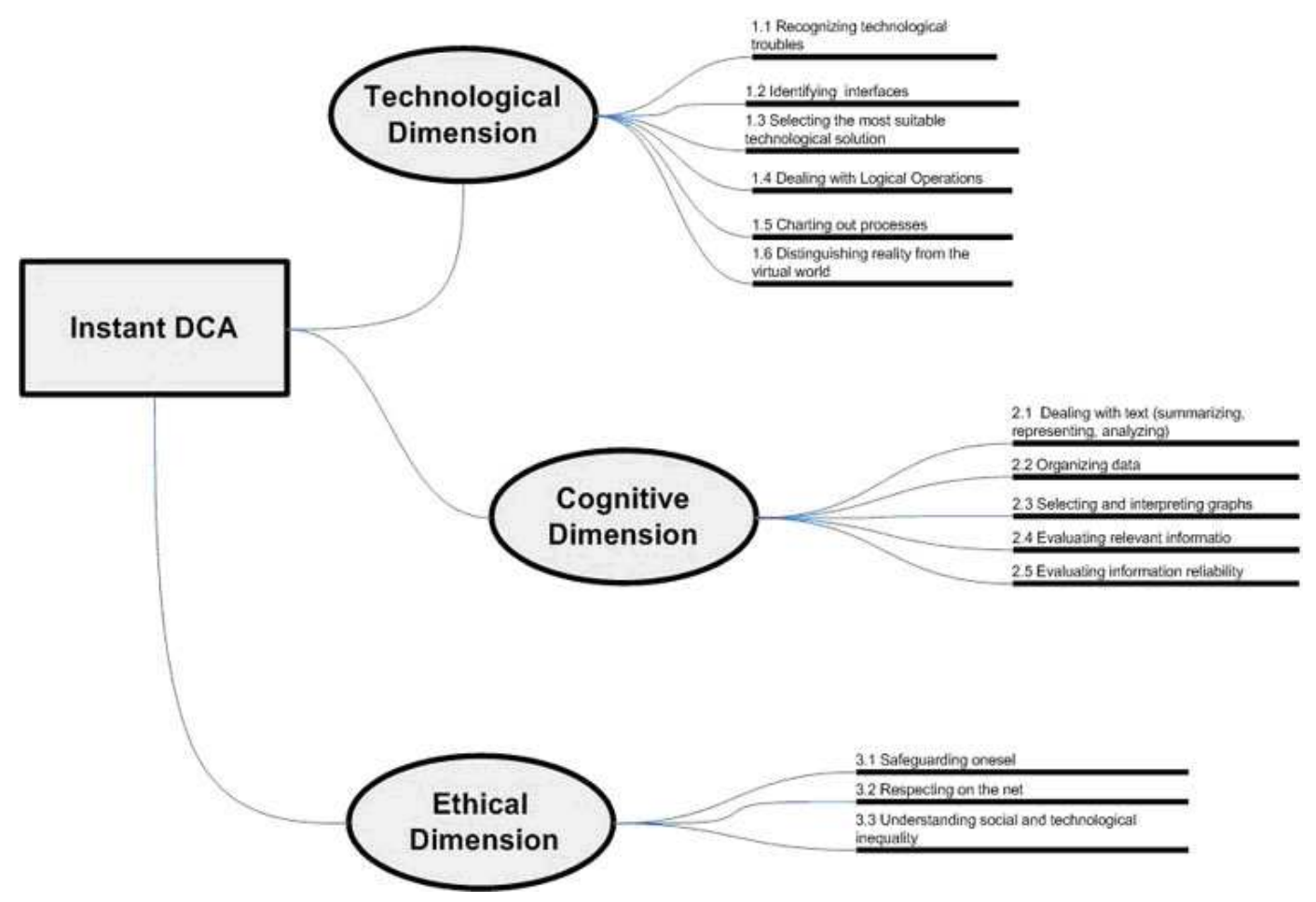

Figure 1: draft of the students' dimensions to be analyzed by the questionnaire Submitted for publication in a chapter of the book "Issues on Information and Media Literacy" edited by M. Leaning 
The ethic section concerns more or less suitable behaviors needed in the use of technologies and more generally on the Internet; these behaviors are at the centre of today's scientific debate due to the differences between the growing technological skills of the net generation and the scars attention the same generation has for the ethical and social consequences of technological behaviors. The section is made up of three sub-sections aimed at: protecting, respecting and knowing (the technological gap).

The time had come for the creation of the information system to be used for the management of digital competences.

\section{The Management Information System for the "Digital Competence"}

As reported in the first section of the paper the local unit of Cassino had the main responsibility for the planning and carrying out the technological instruments to be used for the hitting of the declared targets in the research project.

The author's former experiences on the use of on line information systems for the creation of communities of learning and of practices influencing subjects' knowledge development and skills led him to think about the opportunity of getting the same results in this new situation.

The following remarks can help the reader in better understanding how the web site and the information system structure were planned and defined:

- the author's experience on IT and ICT use for teaching and research led him to deduce that subjects build knowledge in at least three different ways: a) autonomously (mostly constructively, by interacting with phenomena, real or virtual they are), b) by socially interacting with other individuals in a community, where mediation and support from peers play a relevant role, c) being an active part of the society they are immersed in, where emulation of behaviors and codified and socially accepted rules can modify pre-existing learning strategies or determine new ones. As a conclusion subjects will have in their knowledge three components: the individual, the community and the social ones, with their own contents, learning strategies and possible communication channels. Figure 2 drafts the hypothesis of at least a tri-partition for individuals' knowledge (Cartelli, 2006).

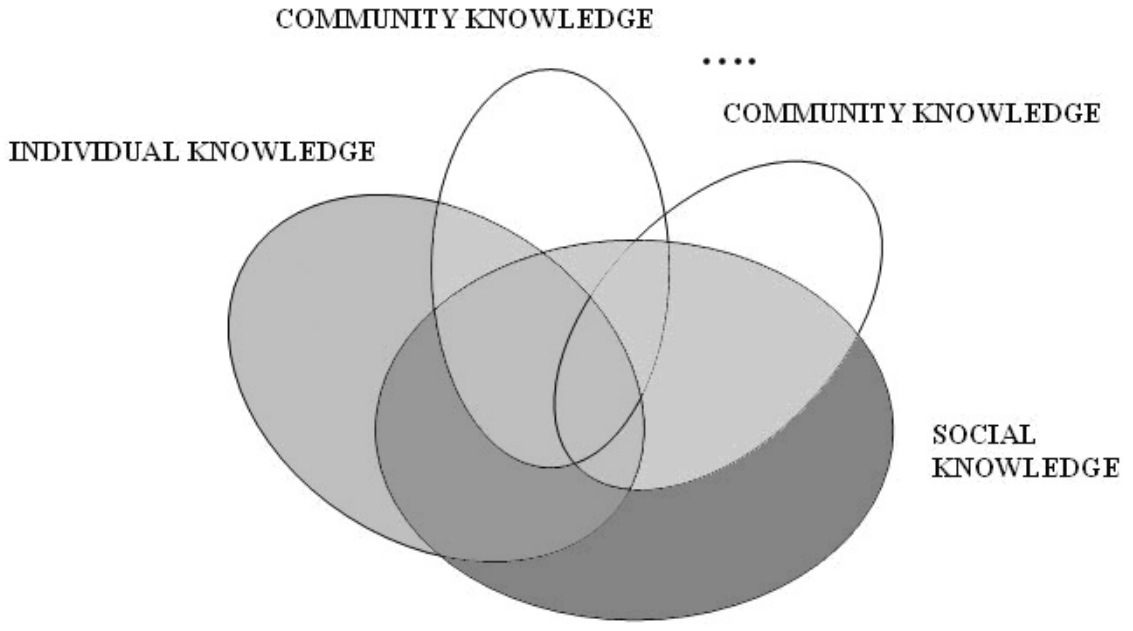

Figure 2: Tri-partition of subjects' knowledge construction 
- The latter viewpoint is concerned with the analysis of knowledge by itself, that is knowledge as an artifact of mankind. One can easily deduce that there are at least three kinds of knowledge:

1. individual knowledge, the one subjects construct and develop while interacting with reality (natural or virtual it is, populated or not by other subjects etc.),

2. community knowledge, the one developed from communities in their entirety; or by using Wenger's words (2004), the knowledge letting people identify themselves in a community where specific signs, symbols and strategies constitute the repertoire of the instruments shared by the members in the community,

3. society knowledge (sometimes identified with scientific knowledge), which is well codified, evaluated and approved from a relevant number of individuals and communities (it could be better represented by means of the scientific paradigms).

In this case, like the one adopted to describe individuals' knowledge, we can use the diagram in figure 2 to describe the different components of knowledge.

- The discussion on knowledge construction and evolution has interest for the dispute still alive in the scientific community on knowledge features (i.e., at the subject level, the community level and in knowledge theory), but has further and deeper consequences on the description of the phenomena which see a strong involvement of ICT use:

- First, it proposes a multi-level structure for knowledge description and construction, which come from three different contributions: personal, community and society.

- Second, it induces to reconsider the totality of the elements to be used when planning the creation of an information system; in other words, whether applying a sociotechnical approach for MIS (Management Information System) introduction in corporate and organizations, or hypothesizing socio-technical ideas in MIS use for public

Social system $\quad$ Technical system

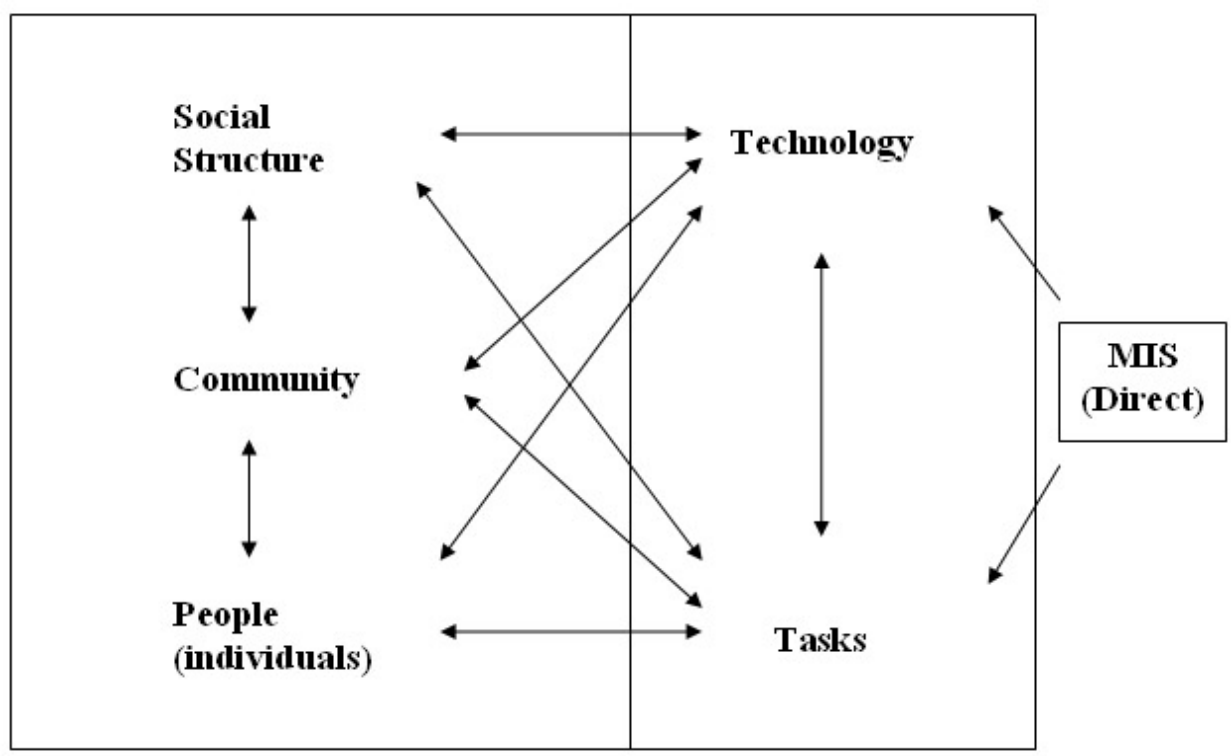

Figure 3: Model for the socio-technical approach to MIS introduction in processes' management 
institutions, all the elements evidenced until now in knowledge management (i.e., individual, community and society) must be considered. Figure 3 drafts the dependencies the author hypothesizes in MIS introduction for processes management (Cartelli, 2007).

The hypotheses and the models reported above were, in the author opinion, general enough to be applied to every situation and especially to the management of the digital competences at all levels. Otherwise stated, by adopting the perspective of the researchers (i.e., the people working on the problem of digital competence analysis and development), three kinds of users accessing the online information system could be identified:

a) individuals (i.e., people belonging to the research group and those who would have liked to join the group); they individually worked on the analysis of the digital competences and on the development of the instruments to be used at school, by producing documents on this topic, items of the tests the students had to be submitted to, etc.

b) community (i.e., the group of the researchers who started the project and decided to work on the digital competences, possibly extended to other people interested in the topic),

c) society (general users); at this level students, teachers, scholars and any kind of interested people could access the documents available in the site and the instruments for assessing the possession of the digital competence; they could also be up to date on the works nationally and internationally published on digital competence and communicate with the research group for exchanging information and propose new problems to analyze.

The structure of the information system reproducing the authors' ideas is drafted in Figure 4 where a snapshot of the data structure and their flow is reported. This scheme doesn't explain how single users access the system and what operations they are allowed to, a short explanation for these features is reported after the image.

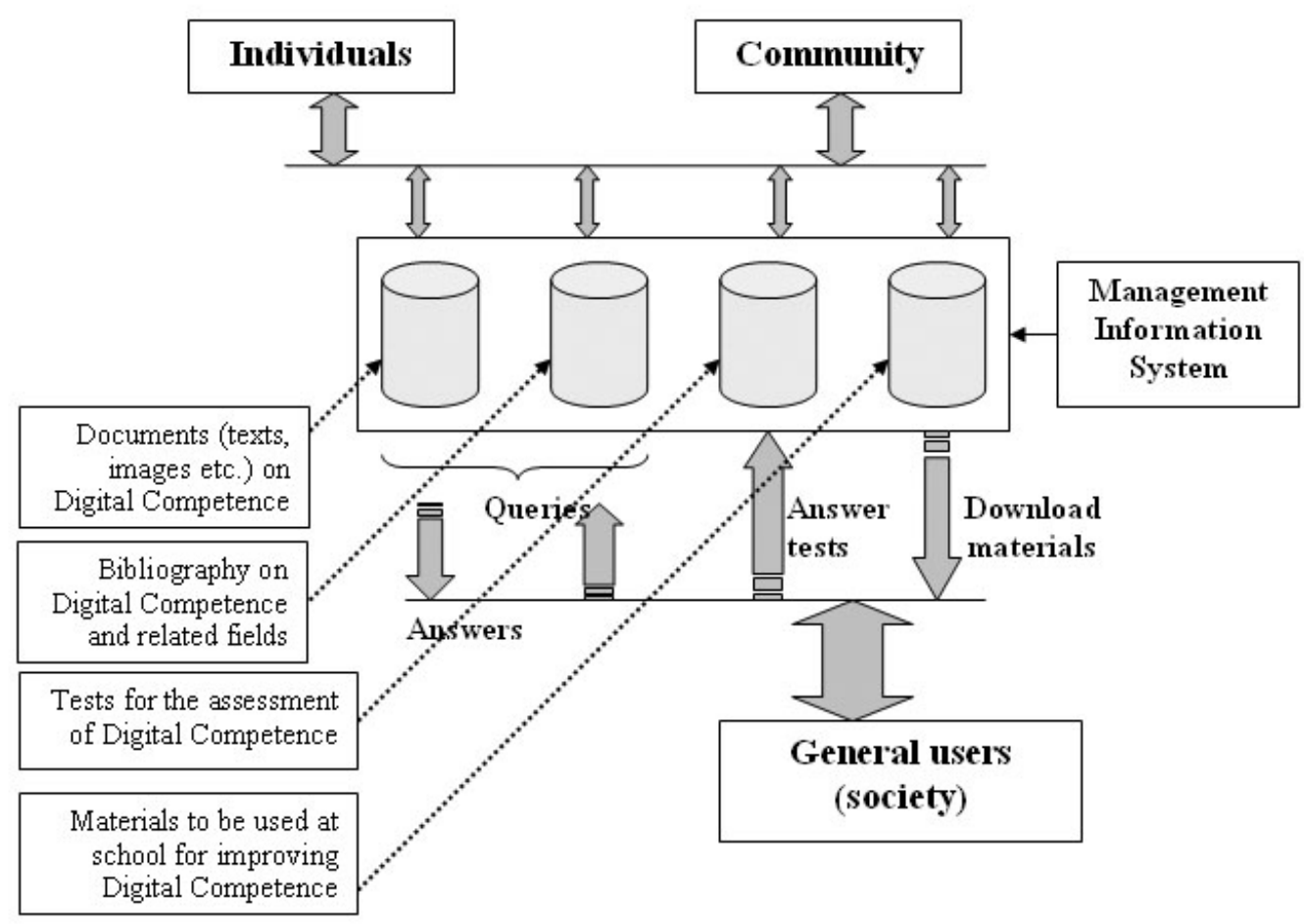

Figure 4: General scheme of the MIS for the management of Digital Literacy 
As regards the repositories of documents and materials on Digital Competence it is easy to recognize the structure of web and/or ftp sites (in both cases http and ftp protocols have been used to access and/or download the documents people are interested in). The main site, still under construction, is already available on the web at the URL: http://www.digitalcompetence.org/.

The creation of the whole site lies on the adoption of Open Source software: Linux as the Operating System, Apache as the web server, PHP as the interface language, PostgreSQL and MySQL as RDBMS. Furthermore the discussion the author had with Antonio Fini, a PhD student at the University of Florence, and the many tools both proprietary and Open Source they tested for the creation of a suitable testing system, led to the choice of the e-learning platform Moodle. It was evaluated good enough for the management of the questionnaires, due to:

- the flexibility in the creation of the questions,

- the easy way of constructing and evaluating the questionnaires,

- the facilities for students' management (i.e., their access and the evaluation of their answers).

The section devoted to the test is included in the web site and the access to the Moodle platform is made easier within it. The site has been designed to be used from international and national users, because both web pages and Moodle pages have been written in Italian and English and in this last case the questions and the situations have been adapted to the English language and culture.

The section of the web site hosting the bibliography on Literacy Competence is a bit different and aims at being an information system, very similar for its features to the BMB online site (Cartelli $\&$ Palma, 2004). The information system is based on: a) a well given database structure, b) different users who can access the database and make the operations they are allowed to, c) a query system and d) a specific data flow. In what follows the above elements are explained in a greater detail:

a. the data base structure lies on four tables: 1) the first one, utente, is used for the data of the contributors and of the scientific administrators, the difference among them is marked by the presence of the character 'R' or 'A' in the rows of the table; 2) the second one, mat$\boldsymbol{b i b}$, contains the data of the materials to be analyzed and for each of them identifies the contributor having to write the corresponding bibliographic cards; 3 ) the schede table follows, it is the table hosting the bibliographical data (i.e. the location, the author/s, the title and every data concerning a publication on Digital Literacy, Digital Competence etc.), four different kinds of materials can be stored in the table: monographs, polygraphs, journals and Web references; 4) the fourth table, bacheca, is an electronic blackboard at all and makes easier for the people involved in the collection of the bibliographical materials the communication,

b. the users accessing the data base have different rights and powers: 1) the user with the least rights on the data is the one who can only query the system to obtain the list of the bibliographic materials, 2) at an upper level are the contributors who can access a special Web area (by means of their ID and password) with a menu of the allowed operations, i.e. they can manage their bibliographic cards and the electronic blackboard, 3) the scientific administrator/s follow, they can manage all the data in the data base and write, modify and certify the bibliographic cards, also if this last operation can be done only once (i.e. when the cards are verified they can no more be accessed from the administrator/s), 4) at the top of the access pyramid is the system administrator who can do all the operations allowed to the scientific administrator/s and can access the verified cards to modify or to delete them, 
c. once the bibliographic cards are compiled from the contributors and verified from the scientific administrator/s they can be queried from a generic user; people interested in the information contained in the data base have three different query pages to access them: a) the first one asks for the author of a given contribution and lets people access the bibliographic records for that author; b) the second one lets the user select one among the different contributors and gives back all the quotations made by that contributor, $d$ ) the third and last one lets the user input one or more words or part of them concerning the location, the author, the series etc. of a given publication and shows all the bibliographic records matching the query constraints,

d. when the system starts the data base is empty and the system administrator has to input the data for at least a scientific administrator; once a scientific administrator is enabled he/she can input the data for one or more contributors and make them access the system, he/she can also input the bibliographic material to be chosen/assigned to the contributors and can input by him/herself the bibliographic cards. When the contributor/s can access the materials to work on they can compile the bibliographic cards for the data base. At last the cards are analyzed and revised from the administrator/s so that they can be read from a general user.

Once the site completed people will be invited to use it (i.e., first of all Italian primary and secondary schools, soon after schools in European countries and all over the world) to test its functionality and validity. Furthermore the software developed for it will be made freely available to people who will like to carry out similar projects.

\section{Conclusion and Implications for Informing Science}

It is probably too early to say what effects and influence the instruments created for the project will have on education, on pedagogical theories and on everyday teaching. In the authors' opinion it will surely contribute in the international debate on digital literacy.

Until now some considerations on the implications for informing science can be made.

Following E. Cohen's (1999) definition for the informing science, it is the discipline which "provides its clientele information in a form, format and schedule that maximizes its effectiveness". When looking at the features of the project, at the experiences described in it and at the data management within the site, it is evident how important the role of informing science can be in determining the effectiveness of information for students and teachers.

Like in the BMB online experience, in fact, in this paper a further step is made. It is proposed the implementation by means of an information system of the practices that people involved in the project had to adopt. In such a case it is evident that the informing science cannot be limited at the role of a discipline working only on data and information management. By expanding the definition of informing science to the implementation of practices it could contribute to answer to the following questions:

- What role informing science can play in the analysis of knowledge phenomena in communities?

- Once in this new domain, can informing science explain knowledge phenomena in the subjects involved in the experiences in the project?

\section{References}

ACRL. (2000). Information literacy competency standards for higher education. Chicago, IL: Association of College \& Research Libraries. 
Alviram A., \& Talmi D. (2006), L'impatto delle tecnologie dell'informazione e della comunicazione sull'educazione, $T D, 38,30-51$.

Ausubel, D. P. (1990). Educazione e processi cognitive. Milan, Italy: Franco Angeli

Bindé, J. Cotbett, J. \& Verity, B. (2005). 21 $1^{\text {st }}$ - century talks: Towards knowledge society. UNESCO.

Bloom, B. S. (1984). Tassonomia degli obiettivi educativi.Teramo: Giunti-Lisciani.

Calvani, A. (Ed.). (2006) Tecnologia, scuola, processi cognitivi. Per una ecologia dell'apprendere. Milan: FrancoAngeli.

Cartelli, A. (Ed.). (2006). Teaching in the knowledge society: New skills and instruments for teachers. Hershey, PA: IGI-Global.

Cartelli, A. (2007). Socio-technical theory and knowledge construction: Towards new teaching paradigms? Journal of Issues in Informing Science and Information Technology, 4, 1-14. Retrieved from http://proceedings.informingscience.org/InSITE2007/IISITv4p001-014Cart339.pdf

Cartelli, A., \& Palma, M. (2004). BMB on line: An information system for paleographic and didactic research. In M. Khosrow-Pour (Ed.), Proceedings of IRMA 2004 International Conference: Innovations Through Information Technology, 45-47. Hershey (PA): IGI-Global.

Cohen, E. (1999). Reconceptualizing information systems as a field of the transdiscipline informing science: From ugly duckling to swan, Journal of Computing and Information Technology, 7(3), 213-219. Retrieved from http://informingscience.org/WhatIS.htm

Committee on Information Technology Literacy. (1999). Being fluent with information technology. Washington (DC): National Academy Press.

Educational Testing Service. (2002). Digital transformation. A framework for ICT literacy. A report from the ICT Literacy Panel. Princeton (NJ): ETS.

Guidolin, U. (2005). Pensare digitale. Teoria e tecniche dei nuovi media. Milano: Mc Graw-Hill.

Kling, R. (1996). Computerization and controversy: Value, conflicts and social choices. San Diego (CA): Academic Press.

Lévy, P. (1996). L'intelligenza collettiva. Per un'antropologia del cyberspazio. Milan, Italy: Feltrinelli.

Tornero, J. M. P. (2004). Promoting digital literacy: Final report (EAC/76/03). Understanding digital literacy. Barcelona: UAB. Retrieved Dec 04, 2007 from http://ec.europa.eu/education/archive/elearning/doc/studies/dig_lit_en.pdf

UNESCO (2002), Recommendations addressed to the UNESCO. Youth Media Education conference. Seville, 15-16 February 2002.

Wenger, E. (2004). Communities of practice: A brief introduction. Retrieved Dec 04, 2007 from http://www.ewenger.com/theory/index.htm

Wurman, R. S. (2001). Information Anxiety 2. Los Angeles: Hayden/Que

\section{Biography}

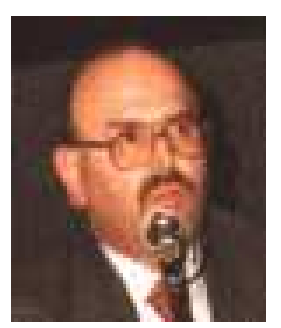

Antonio Cartelli is a researcher in Didactics and special pedagogy. He manages the Laboratory for Teaching-Learning Technologies and the Centre for ICT and on line teaching in the Faculty of Humanities at the University of Cassino - Italy. Among his interests are: misconceptions, mental schemes, Information Systems for research and teaching, Web Technologies in teaching research and their everyday application for the improvement of teaching and learning. He is also author of many papers and books concerning the themes he is interested in. 